\title{
Vascular Endothelial Growth Factor - Marker for Proliferation in Thyroid Diseases?
}

\author{
Authors \\ Affiliation \\ Key words \\ - VEGF \\ - VEGF receptors 1 and 2 \\ goiter \\ - recurrent \\ - multinodular \\ - Graves' disease
}

P. Malkomes, E. Oppermann, W. O. Bechstein, K. Holzer

Department of General Surgery, University Hospital of Frankfurt, Frankfurt, Germany received 20.04.2012

first decision 17.08.2012

accepted 24.09.2012

\section{Bibliography}

DOI http://dx.doi.org/

10.1055/s-0032-1327634

Exp Clin Endocrinol Diabetes

2013; 121: 6-13

(C) J. A. Barth Verlag in

Georg Thieme Verlag KG

Stuttgart · New York

ISSN 0947-7349

\section{Correspondence}

\section{P. Malkomes}

Department of General Surgery University Hospital of Frankfurt Theodor-Stern Kai 7 60590 Frankfurt

Germany

Tel.: +49/69/63014177

Fax: + 49/69/63015854

Patrizia.Malkomes@kgu.de

\section{Abstract \\ $\nabla$}

Vascular endothelial growth factor (VEGF) is a critical regulator of angiogenesis and is involved in tumor development. To date, the role of VEGF in benign diseases of the thyroid is not well known. The purpose of the present study is to determine the expression of VEGF and its receptors in primary cultures of human thyrocytes.

Methods: 50 patients with uninodular $(n=11)$, multinodular $(n=15)$, recurrent goiter $(n=14)$ and Graves' disease $(n=10)$ were enrolled. Nodular and corresponding paranodular tissue was obtained after surgery and investigated. RNA and protein were extracted from primary thyrocyte cultures. PCR, western blot and ELISA were performed to evaluate VEGF isoforms and VEGF receptor 1 and 2 .

\section{Introduction}

In 1989 vascular endothelial growth factor (VEGF) was identified as an angiogenic factor [1]. VEGF is a potent stimulator of endothelial cell growth and a critical regulator of both physiological and pathological angiogenesis [2].

VEGF binds to 2 different tyrosine kinase receptors VEGFR-1 (flt-1) and VEGFR-2 (flk-1/KDR), mainly expressed on endothelial cells [3].

VEGFR-1 may play a more regulatory role in angiogenesis, whereas VEGFR-2 is responsible for signaling [4]. In addition, VEGF mediates inflammatory reactions [5].

Via a paracrine mechanism VEGF signaling plays a critical role in tumor angiogenesis, hence, high expression of VEGF and its receptors was shown in a number of human cancers such as gastric cancer [6], breast cancer [7], colon cancer [8], ovarian cancer [9] and prostate cancer [10]. Increased expression of VEGF was even linked to poor outcome and increased risk for metastasis
Results: Significantly increased transcription and protein expression of VEGF and its receptors were detected in nodular tissue of uninodular and recurrent goiter compared to the corresponding normal tissue. Active secretion of VEGF by thyrocytes was confirmed by ELISA. In multinodular goiter, no difference could be found between nodular and corresponding paranodular tissue in terms of expression of VEGF or its receptors. Furthermore, we found the highest levels of VEGF and its receptors in tissue obtained from patients with Graves' disease.

Conclusion: Increased expression of VEGF and its receptors might be crucial in the proliferation of thyrocytes and therefore may contribute to the development of goiter and goiter recurrence.
High expression of VEGF in thyroid cancer was found to be correlated with advanced tumor stage, lymph node metastasis and increased risk of recurrence [20-22]. Therefore, VEGF inhibitors are approved for the treatment of advanced thyroid cancers [23].

Furthermore, VEGF seems to be involved in goiter development by inducing endothelial cell proliferation and angiogenesis. Recently, in clinical studies it was demonstrated, that treatment with tyrosine kinase inhibitors leads to hypothyroidism in over $40 \%$ of patients, indicating a functional role of the VEGF signaling pathway even in normal thyroid tissue [24,25]. 


\begin{tabular}{|c|c|c|}
\hline $\begin{array}{l}\text { Target } \\
\text { genes }\end{array}$ & $\begin{array}{l}\text { Sequence of forward and reverse primer } \\
\left(5^{\prime}-3^{\prime}\right)\end{array}$ & Size (bp) \\
\hline VEGF-A & $\begin{array}{l}\text { 5'-TGC CTT GCT GCT CTA CCT CC-3' } \\
\text { 5'-TCA CCG CCT CGG CTT GTC AC-3' }\end{array}$ & $\begin{array}{l}\text { VEGF }_{121}-410 \\
\text { VEGF }_{145^{-}}-480 \\
\text { VEGF }_{165^{-}}-540 \\
\text { VEGF }_{189^{-}} 610 \\
\text { VEGF }_{209^{-}}-660\end{array}$ \\
\hline VEGFR-1 & $\begin{array}{l}\text { 5'-GAT GTT GAG GAA GAG GAG GAT T-3' } \\
\text { 5'-AAG CTA GTT TCC TGG GGG TAT A-3' }\end{array}$ & 1100 \\
\hline VEGFR-2 & $\begin{array}{l}\text { 5'-GAT GTG GTT CTG AGT CGG TCT-3' } \\
\text { 5'- CAT GGC TCT GCT TCT CCT TTG-3' }\end{array}$ & 560 \\
\hline GAPDH & $\begin{array}{l}\text { 5'-ATC TTC CAG GAG CGA GAT CC-3' } \\
\text { 5'-ACC ACT CAC ACG TTG GCA GT-3' }\end{array}$ & 509 \\
\hline TPO & $\begin{array}{l}\text { 5'-AGA TCT GCT GAG CAT CAT TG-3' } \\
\text { 5'-CAT CAG GAG CTC AGA ATA GCG-3' }\end{array}$ & 330 \\
\hline TSHR & $\begin{array}{l}\text { 5'-TAC TTC AGT CCA AGG ATA TG-3' } \\
\text { 5'-GCA AGC TCT GCA TAC TGC TCT-3' }\end{array}$ & 361 \\
\hline $\mathrm{Tg}$ & $\begin{array}{l}\text { 5'-GAT CTT ACT GAG TGG CTA CA-3' } \\
\text { 5'-ACT GCA CCG CCT GAT AGT CG-3' }\end{array}$ & 682 \\
\hline
\end{tabular}

To date, the role and expression of VEGF and its receptors in normal and benign diseases of the thyroid have rarely been investigated.

This study was performed to investigate the expression pattern of VEGF and its receptors in thyrocytes from normal thyroid tissue and benign thyroid diseases.

\section{Materials and Methods}

$\nabla$

\section{Patients}

50 patients ( $q=38, \sigma^{x}=12$ ) were enrolled in the clinical study. The protocol was approved by the ethics committee of the University Hospital of Frankfurt and preoperative written consent was obtained from all patients. The patients were divided into 4 groups according to the diagnosis, 11 patients with uninodular goiter (UN), 15 with multinodular goiter (MN), 10 with Graves' disease $(G)$ and 14 patients with recurrent nodular goiter (R) were operated on and included.

Recurrent goiter was defined as development or regrowth of nodules after the first operation of the thyroid gland as revealed by the patient's history. The indication for reoperation was one or more nodular growths as detected by ultrasound. All patients fulfilled these criteria.

\section{Tissue samples and cell culture}

Thyroid tissue was obtained after surgical resection. All tissue samples were examined and characterized by a pathologist and when possible, nodular and adjacent non-tumor or paranodular tissues were acquired. In the case of Graves' disease only paranodular tissue was investigated.

The thyroid tissue was minced into small fragments, washed 3 times with HBSS (Hank's balanced salt solution) containing $50 \mathrm{U} / \mathrm{ml}$ penicillin and $50 \mu \mathrm{g} / \mathrm{ml}$ streptomycin followed by enzymatic dissociation with $246 \mathrm{U} / \mathrm{ml}$ collagenase I for 60-90 min at $37^{\circ} \mathrm{C}$. After digestion, thyrocytes were filtered through a $100 \mu \mathrm{m}$ nylon mesh (Becton Dickinson; Heidelberg, Germany), pelleted and washed with HBSS.

Thyrocytes were resuspended and counted in Neubauer counting chamber before plating. Cell viability was assessed using trypan blue exclusion ( $>98 \%$ ). Thyrocytes were plated at a den- sity of 50000 cells/well in 6-well plates and were cultured in DMEM supplemented with $10 \%$ fetal calf serum, 200 mM Hepes, $50 \mathrm{U} / \mathrm{ml}$ penicillin and $50 \mu \mathrm{g} / \mathrm{ml}$ streptomycin. The monocultures were maintained in a standard humidified incubator at $37^{\circ} \mathrm{C}$ in a $5 \% \mathrm{CO}_{2}$ atmosphere. On day 1 medium was changed to remove cell debris, on day 4 harvesting was performed. Thyrocyte culture by this procedure has no detectable stromal or endothelial contamination, as attested to by immunohistochemistry and PCR.

\section{Immunofluorescence}

Primary thyrocyte cultures were washed with PBS (phosphate buffered saline) and fixed with ice cold acetone for $10 \mathrm{~min}$. After fixation, cells were washed again followed by incubation with primary antibody for $60 \mathrm{~min}$ at $4{ }^{\circ} \mathrm{C}$. Primary antibodies were as follows: mouse monoclonal anti-cytokeratine 18 (clone Ks18.04) and 19 (clone Ks19.10) (Progen Biotechnik; Heidelberg, Germany, diluted 1:2), mouse monoclonal anti-fibroblast antibody (Acris antibodies; Hiddenhausen, Germany, diluted 1:100), mouse anti-von Willebrand factor (Dako; Hamburg, Germany, diluted 1:50). After incubation with primary antibodies, cultures were washed twice with wash buffer $(0.5 \%$ BSA in PBS without $\mathrm{Ca}++$ and $\mathrm{Mg}++$ ) followed by incubation with secondary antibody for $60 \mathrm{~min}$ at $4{ }^{\circ} \mathrm{C}$ (NL493 [NorthernLights] - conjugated donkey anti-mouse IgG, diluted to $1: 100$, (R\&D Systems; Wiesbaden-Nordenstadt, Germany). All antibodies were diluted with $0.5 \%$ BSA (bovine serum albumin) in PBS. Cell cultures were rinsed 3 times in wash buffer and finally mounted with Prolong antifade Kit (Molecular Probes; Eugene, Oregon). Staining was visualized microscopically by Zeiss Z-1 Observer (Zeiss; Göttingen, Germany). A negative control was also carried by incubating cell cultures with mouse IgG1 (Dako Cytomation, Denmark). All controls were consistently negative.

\section{RNA isolation, CDNA synthesis, semiquantitative} RT- PCR, quantitative PCR

Total RNA was extracted using RNeasy kit (Qiagen GmbH; Hilden, Germany) according to the manufacturer's instructions. cDNA was synthesized from $1 \mu \mathrm{g}$ of total RNA with Oligo (dT) Primer using AffinityScript QPCR cDNA synthesis kit (Stratagene; CA, USA) according to the manufacturer's instructions. Thyroid peroxidase (TPO), TSH receptor (TSHR), Thyreoglobulin (Tg), VEGF-A and VEGFR-1 and -2 transcripts were analyzed by performing reverse-transcriptase PCR (RT-PCR) ( $\bullet$ Table 1). RNA amount and RNA quality were analyzed using Nanovue (GE Healthcare, USA) and Bioanalyzer (Agilent Technologies, USA) respectively. Semi-quantitative RT-PCR was carried out in a $50 \mu \mathrm{l}$ reaction mixture for each assay containing $1 \mu \mathrm{l}$ of DNA template, $5 \mu$ of $10 \times$ Titanium Taq PCR Buffer, $1 \mu$ l of $50 \times$ Titanium Taq DNA polymerase (Takara Bio Europe/Clontech; Saint Germainen-Laye, France), $1 \mu$ l of dNTPs ( $10 \mathrm{mM}$ of each dATP, dCTP, dGTP, dTTP from Takara Bio Europe/Clontech) and $1 \mu$ of primer mix $-50 \mathrm{pmol}$, of each forward and reverse primer ( $\bullet$ Table 1 ) using a Tpersonal Thermocycler (Biometra GmbH; Goettingen, Germany). PCR parameters were as follows: initial denaturation at $95^{\circ} \mathrm{C}$ for $5 \mathrm{~min}$ followed by 35 cycles $30 \mathrm{~s}$ denaturation at $95^{\circ} \mathrm{C}$; $30 \mathrm{~s}$ of annealing at $64^{\circ} \mathrm{C}$ for VEGF-A, VEGFR-1, and VEGFR-2, $58^{\circ} \mathrm{C}$ for GAPDH and $55^{\circ} \mathrm{C}$ for TPO, TSHR and Tg; $30 \mathrm{~s}$ elongation at $72^{\circ} \mathrm{C}$ and, finally, a further elongation step at $72^{\circ} \mathrm{C}$ for $10 \mathrm{~min}$. Ethidium bromide stained amplified fragments were separated by agarose gel electrophoresis (2\%), visualized and 
Table 2 Primers for QPCR from SABiosciences.

\begin{tabular}{|lllr} 
Target genes & $\begin{array}{l}\text { Accession } \\
\text { number }\end{array}$ & $\begin{array}{l}\text { Reference } \\
\text { Position }\end{array}$ & Size (bp) \\
\hline VEGF-A & NM 003376 & 2649 & 183 \\
\hline VEGFR-1 & NM 002019 & 5144 & 58 \\
\hline VEGFR-2 & NM 002253 & 629 & 151 \\
\hline beta-Actin & NM 0011013 & 1222 & 191 \\
\hline
\end{tabular}

analyzed by Gel Doc 100 with molecular analyst software (BioRad Laboratories; Munich, Germany).

Densitometric analysis was performed and signal was evaluated as area $\left(\mathrm{mm}^{2}\right)$. GAPDH was used as housekeeping gene and a 100 bp DNA ladder was used as molecular weight marker.

The results were confirmed by real-time quantitative PCR (QPCR) using RT2 ${ }^{2}$ SYBR-Green/Rox qPCR master mix and gene specific primers ( $\Theta$ Table 2 ) (both from SABioscience, USA) according to the manufacturer's protocol. Amplification of genes was performed using MX3005P (Stratagene, USA). 100 ng of cDNA was used in qPCR reaction in duplicates. The dissociation curve was checked at the end of each PCR reaction. GAPDH and $\beta$-Actin were used as housekeeping genes and for normalization. Gene expression (fold change) was calculated using $\Delta \Delta C_{\mathrm{t}}$ method after normalizing nodular tissue with each corresponding paranodular or normal adjacent tissue.

\section{Protein isolation and western blot}

Thyrocytes cultures were rinsed twice with ice-cold PBS and lysed for $10 \mathrm{~min}$ on ice in lysis buffer (50 mM HEPES, $200 \mathrm{mM}$ $\mathrm{NaCl}, 0.2 \mathrm{mM}$ MgSO4, $0.4 \mathrm{mM}$ phenylmethylsulfonyl fluoride, $2 \%$ Triton-X-100, $10 \mu \mathrm{g} / \mathrm{mL}$ leupeptine, $10 \mu \mathrm{g} / \mathrm{mL}$ aprotinine, $0.02 \%$ soybean trypsin inhibitor, $0.2 \mathrm{mM}$ ortho-vanadate (SigmaAldrich; Taufkirchen, Munich, Germany). Cell lysates were centrifuged for $10 \mathrm{~min}$ at $12000 \times \mathrm{g}$ at $4^{\circ} \mathrm{C}$. Protein concentration of the supernatants was determined by Coomassie Plus protein assay kit (Pierce; Rockford, IL, USA) and were measured spectrophotometrically at $595 \mathrm{~nm}$ by Tecan Infinite ${ }^{\circledR}$ M 200 microplate reader (Tecan-Deutschland; Crailsheim, Germany). Protein was denatured in Laemmli sample buffer (Bio-Rad Laboratories; Munich, Germany) with $\beta$-mercaptoethanol (Sigma; Taufkirchen, Germany), boiled for $5 \mathrm{~min}$, transferred on ice and subjected to sodium dodecyl sulfate polyacrylamide gel electrophoresis (SDS-PAGE) $(50 \mu \mathrm{g}$ per lane). PeqGold prestained protein marker IV (Peqlab Biotechnologie GmbH; Erlangen, Germany) was used as molecular weight standards. After separation, protein was transferred to a polyvinylidene difluoride membrane (Hybond P; GE Healthcare; Munich, Germany). Blots were blocked with $10 \%$ low-fat milk for $1 \mathrm{~h}$ at room temperature followed by incubation with primary antibodies from Santa Cruz Biotechnology (rabbit polyclonal VEGF [total protein], 1:200; rabbit polyclonal VEGFR-1, 1:200; mouse polyclonal VEGFR-2, clone A-3, 1:200 and mouse monoclonal $\beta$ Actin, clone AC-15, 1:1000; Sigma) overnight at $4^{\circ} \mathrm{C}$. Blots were then washed $3 \times$ with Towbin buffer with $0.5 \%$ Tween 20 followed by incubation for $30 \mathrm{~min}$ with secondary antibody from Millipore GmbH; Schwalbach/Ts, Germany (polyclonal goat antirabbit IgG, 1:5000; goat anti-mouse IgG, 1:5000, both HRP conjugated) at room temperature. All antibodies were diluted in Towbin Buffer with $0.5 \%$ Tween 20 and $0.5 \%$ bovine serum albumin. Blots were then washed and incubated with ECL (Enhanced Chemiluminescence-ECL detection kit from GE Healthcare; Munich, Germany) and exposed to ECL Hyperfilm (GE healthcare), developed in Curix 60 (Agfa;
Dusseldorf, Germany) and documented by Gel Doc 100. $\beta$ Actin was used as loading control.

\section{ELISA}

Cell culture supernatant was quantified using VEGF ELISA-kit (R\&D systems; Wiesbaden-Nordenstadt, Germany). The assay was done according to the manufacturer's instructions. Briefly, $200 \mu \mathrm{l}$ samples (1:30), standard, and controls were dispensed into microplate wells precoated with anti-VEGF monoclonal antibody, and then incubated for $120 \mathrm{~min}$ at room temperature. After incubation, the wells were washed 5 times and $50 \mu l$ of horse radish peroxidase (HRP) conjugated VEGF was added and incubated for $60 \mathrm{~min}$ at room temperature. After 5 washes, $100 \mu \mathrm{l}$ of chromogenic enzyme substrate solution was added and incubated for $30 \mathrm{~min}$ at RT; $50 \mu \mathrm{l}$ stop solution was added and spectrophotometrically measured using Infinite ${ }^{\circledR}$ M 200 microplate reader (Tecan-Deutschland; Crailsheim, Germany) at $405 \mathrm{~nm}$. The sample concentration was calculated based on standard concentrations.

\section{Statistical analysis}

Data were analyzed using commercially available software Bias for Windows, Version 8.3.7 (H. Ackermann, Johann-Wolfgang Goethe University, Department of Mathematics). Data are presented as means \pm SEM. Non-parametric tests were used due to irregularly distributed data. The groups were compared using Kruskal-Wallis'test. Paired data (nodular and paranodular tissue) were analyzed using Wilcoxon's test. Statistical significance was achieved at $\mathrm{p}<0.05$.

\section{Results \\ $\nabla$}

\section{Characterization of thyrocyte cultures}

The primary cell cultures showed the typical morphology of thyrocytes on microscopic examination, i.e., small, elongated cells arranged as cellular isles ( $\boldsymbol{\bullet}$ Fig. $\mathbf{1 a}, \mathbf{b}$ ).

Immunohistochemical staining demonstrated the cells to be positive for cytokeratin 18 ( 0 Fig. 1c, d) and so to be of epithelial origin. The cells were negative for cytokeratin 19, including fibroblasts specific antigen and Factor VIII (von Willebrand factor), showing no contamination of stromal and endothelial cells, yielding primary thyrocyte culture purity of greater than $98 \%$.

In addition, using RT-PCR all cell cultures were positive for thyroid peroxidase (TPO), TSH receptor (TSHR) and thyreoglobuline $(\mathrm{Tg})$, namely indicating the presence of thyrocytes ( $\mathbf{0}$ Fig. 1e).

\section{mRNA expression of VEGF-A, VEGFR-1 and - 2 in human thyrocytes}

VEGF-A isoforms were expressed by $99 \%$ of all thyrocyte cultures. Here expression of $\mathrm{VEGF}_{145}$ was significantly higher in nodular tissue from uninodular goiter compared with corresponding normal tissue $\left(\mathrm{VEGF}_{145}=70 \pm 7\right.$ counts $/ \mathrm{mm}^{2}[\mathrm{UN}]$ vs. $46 \pm 7$ counts $/ \mathrm{mm}^{2}$ [P]; $\mathrm{p}<0.05$ ) ( $\odot$ Fig. $2 \mathrm{a}$ ). In recurrent goiter we found higher amounts of $\mathrm{VEGF}_{145}$ mRNA in nodular tissue compared to paranodular tissue, but without statistical significance ( $\odot$ Fig. 2c). VEGF-R1 and -R2 were significantly increased in nodular vs. paranodular tissue, as shown in uninodular goiter (VEGF-R $1=479 \pm 68$ counts $/ \mathrm{mm}^{2}$ [UN] vs. $133 \pm 47$ counts $/ \mathrm{mm}^{2}$ [P]; $\quad \mathrm{p}<0.05 ; \quad$ VEGF-R $2=710 \pm 72$ counts $/ \mathrm{mm}^{2} \quad[\mathrm{UN}]$ vs. $361 \pm 52$ counts $/ \mathrm{mm}^{2}[\mathrm{P}] ; \mathrm{p}<0.05$ ) ( $\bullet$ Fig. $2 \mathrm{a}$ ) and recurrent 

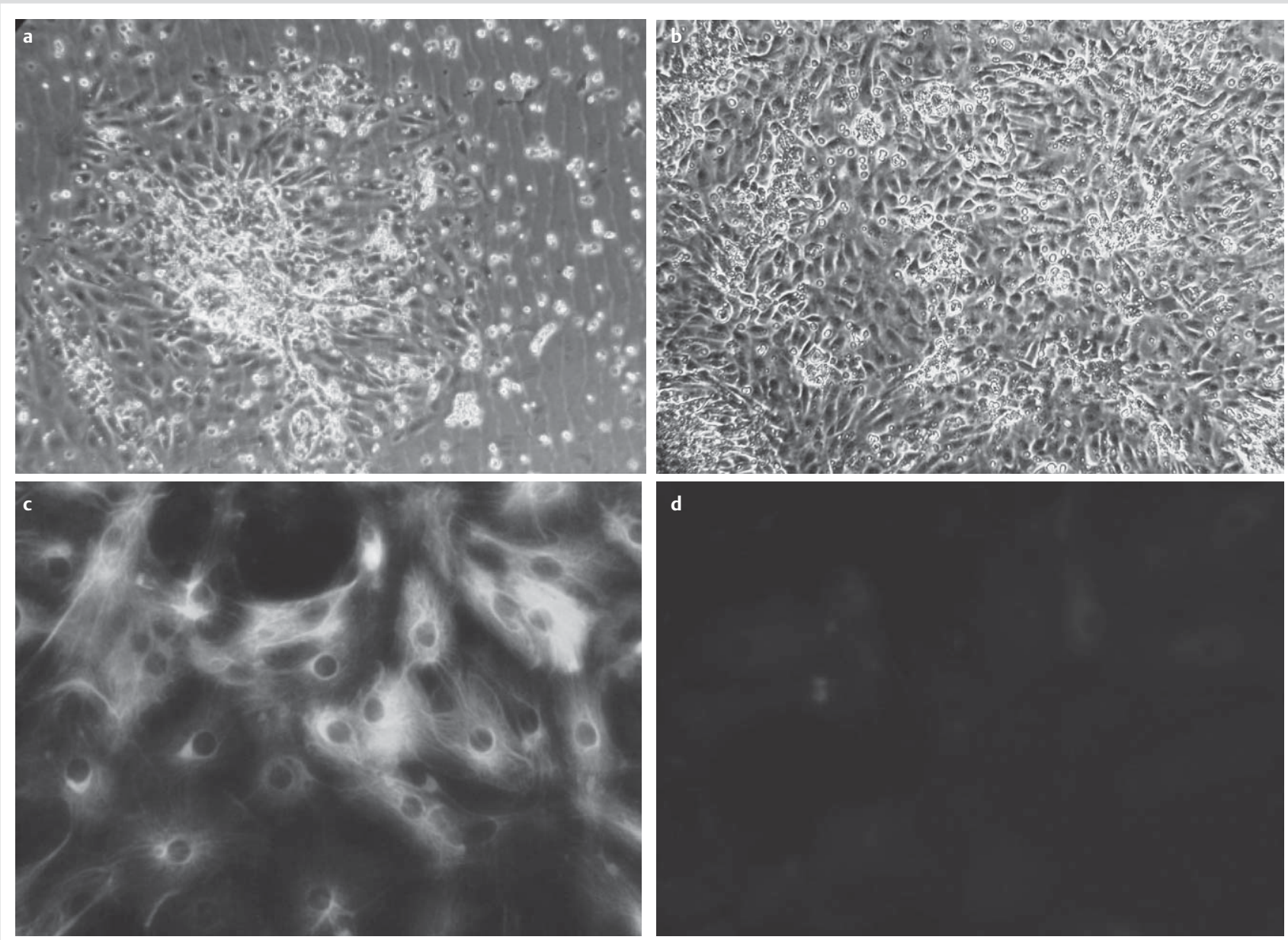

e $\quad$ RT-PCR

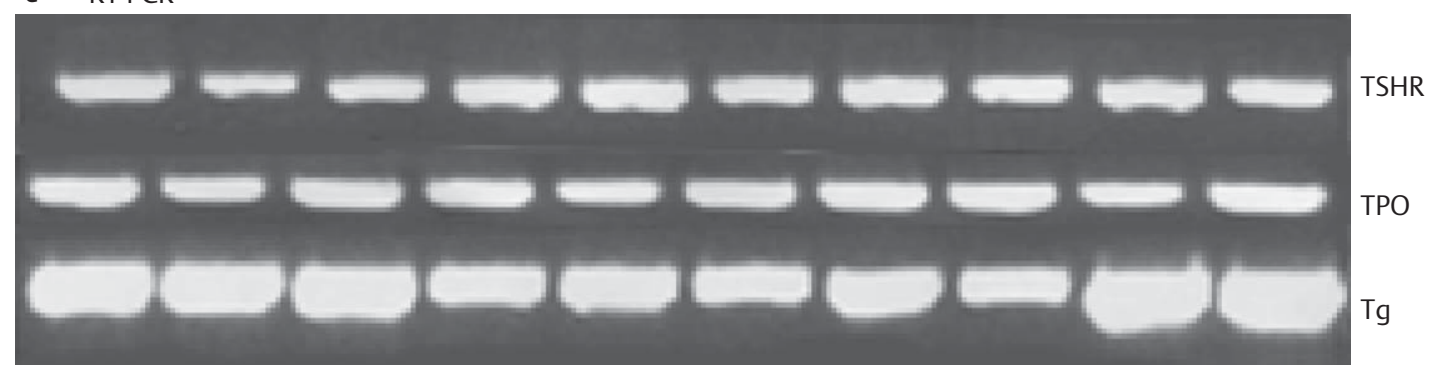

Fig. 1 Characterization of primary culture of thyrocytes. a Primary thyrocyte culture appearing in clusters on day $1, \mathbf{b}$ that reach $95 \%$ confluency on day 4 (both 10X). c Immunofluorescence staining in primary culture of thyrocytes showing positive cytokeratin $18 \mathbf{d}$ and negative isotype control. e RT-PCR confirmed the presence of thyrocyte specific markers TSHR, TPO and Tg.

goiter (VEGF-R1 $=428 \pm 46$ counts $/ \mathrm{mm}^{2}[\mathrm{UN}]$ vs. $72 \pm 20$ counts $/$ $\mathrm{mm}^{2}[\mathrm{P}] ; \mathrm{p}<0.05 ;$ VEGF-R2 $=617 \pm 56$ counts $/ \mathrm{mm}^{2}$ [UN] vs. $174 \pm 45$ counts $/ \mathrm{mm}^{2}[\mathrm{P}] ; \mathrm{p}<0.05$ ) (० Fig. $2 \mathrm{c}$ ).

In Graves' disease we found the highest levels of $\mathrm{VEGF}_{145}$, VEGFR-1 and - 2 mRNA compared to the paranodular tissue of the other 3 groups, but without reaching statistical significance (॰ Fig. 2d).

Interestingly, in tissue from patients with multinodular goiter we did not find any significant difference in the expression levels of VEGF and its receptors between nodular and paranodular tissue ( $\bullet$ Fig. 2b).

The results of RT-PCR were confirmed by performing QPCR. The results are presented as fold change after normalizing nodular tissue with each corresponding paranodular tissue ( $\bullet$ Table 3a), as well as after normalizing paranodular tissue of Graves' disease with paranodular tissue of the other 3 groups ( $\bullet$ Table $\mathbf{3 b}$ ).

Protein expression of VEGF (total), VEGFR-1 and -2 in human thyrocytes

The VEGF protein was highly expressed in all cell cultures obtained. Furthermore, expression of the receptor proteins was demonstrated in over $90 \%$ of the isolated thyrocytes. In uninodular and recurrent goiter, protein expression of VEGF was higher in nodular compared to paranodular tissue as shown in $\bullet$ Fig. $3 a$. The same results were detected for protein expression of VEGFR-1 and VEGFR-2 ( $\bullet$ Fig. $3 a)$.

Interestingly, again in multinodular goiter we could not find any difference in protein expression between paranodular and nodular tissue as seen at mRNA level ( $\bullet$ Fig. 3a). 


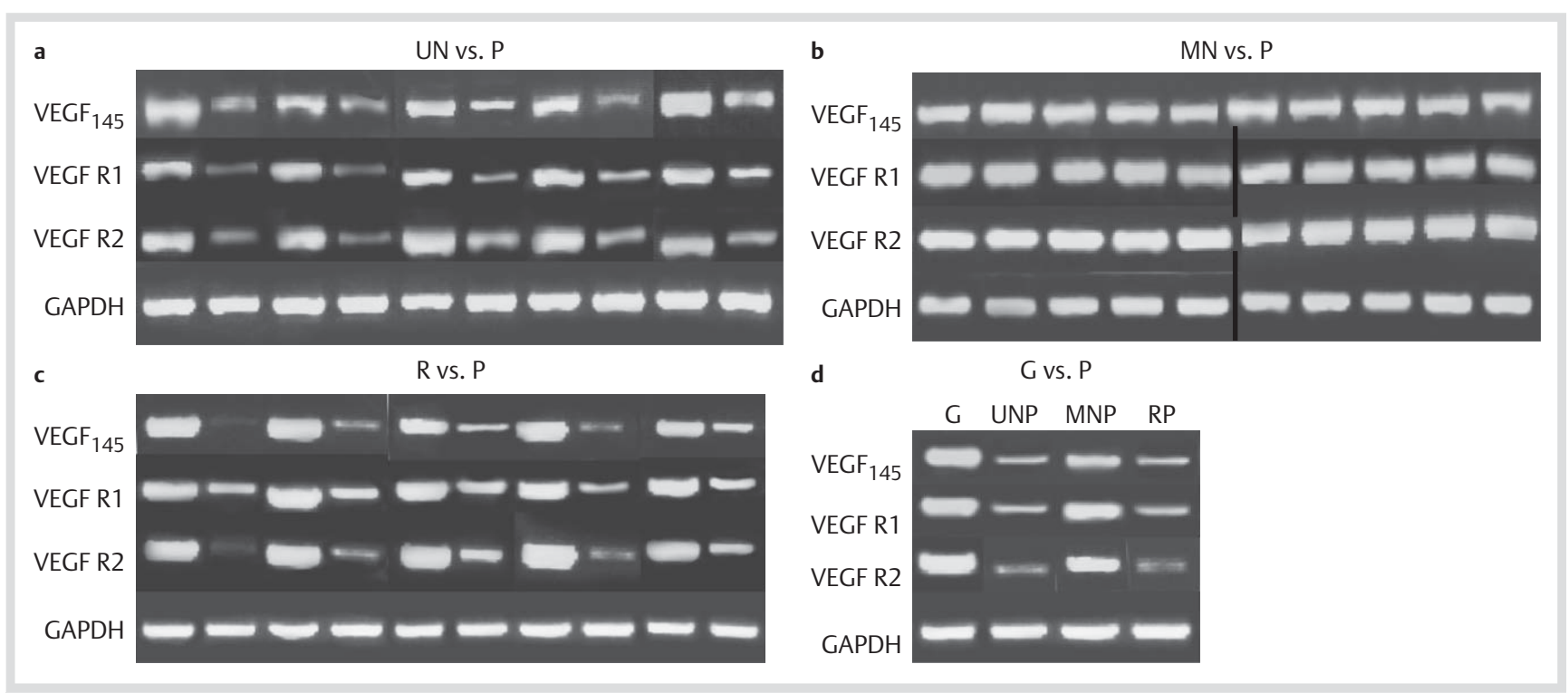

Fig. 2 Analysis of VEGF 145 , VEGFR-1 and -2 in primary culture of thyrocytes by RT-PCR. a-c Expression in nodular tissue of uninodular, multinodular and recurrent goiter (UN, MN, R) vs. their corresponding paranodular tissue (P). Depicted were 5 representative bands from each group. $\mathbf{d}$ Expression in paranodular tissue of Graves' disease (G) vs. paranodular tissue of uninodular, multinodular and recurrent goiter (UNP, MNP, RP). Depicted was 1 representative band from each group.

\begin{tabular}{|c|c|c|c|}
\hline \multicolumn{4}{|c|}{ a) Nodular tissue vs. paranodular tissue } \\
\hline Group & VEGF & VEGFR-1 & VEGFR-2 \\
\hline UN & +15,78 (upregulation) & $+10,28$ (upregulation) & $+8,28$ (upregulation) \\
\hline MN & +1,57 (no regulation) & $-1,64$ (no regulation) & $+1,26$ (no regulation) \\
\hline $\mathrm{R}$ & $+41,53$ (upregulation) & $+28,44$ (upregulation) & $+8,06$ (upregulation) \\
\hline \multicolumn{4}{|c|}{ b) Graves' disease vs. paranodular tissue of UN, MN, R } \\
\hline Group & VEGF & VEGFR-1 & VEGFR-2 \\
\hline UNP & +3,34 (upregulation) & $+8,11$ (upregulation) & $+2,26$ (upregulation) \\
\hline MNP & +1,43 (no regulation) & 3,18 (upregulation) & $+1,68$ (no regulation) \\
\hline RP & +19,29 (upregulation) & $+14,32$ (upregulation) & $+30,91$ (upregulation) \\
\hline
\end{tabular}

Table 3 Results of QPCR (fold change).

In the present study, we were able to demonstrate co-expression of VEGF and its receptors VEGFR-1 and -2 in normal human thyrocytes and in benign diseases of the thyroid. In addition, we detected active secretion of VEGF protein by thyrocytes in the supernatant and measured higher concentrations of VEGF protein in nodular tissue of uninodular and recurrent goiter compared to the corresponding normal tissue. Furthermore, the present data demonstrate large amount of VEGF protein in nodular and paranodular tissue of multinodular goiter, that might contribute to the proliferating effect on thyrocytes and its involvement in goiter development.

These findings contradict previous studies, which reported weak expression of VEGF in benign nodules of the thyroid with no differences between normal thyroid tissue and benign adenomas $[27,28]$. Itoh et al. did not even find any expression of VEGF in normal thyroid tissue and only negative or weak expression in adenomatous goiter [29]. These discrepancies may be explained by the methodological approach used. In previous studies, fresh frozen tissue or formalin-fixed paraffin-embedded tissue was primarily used for the investigation while our study examined pure cultures of freshly isolated thyrocytes, thus, excluding possible endothelial contamination and antigen masking of targets of interest due to formalin-fixation. With regards to the expression of the VEGF receptors, only immunohistochemistry staining of VEGF receptors expression on human thyrocytes of benign thyroid diseases has been shown 


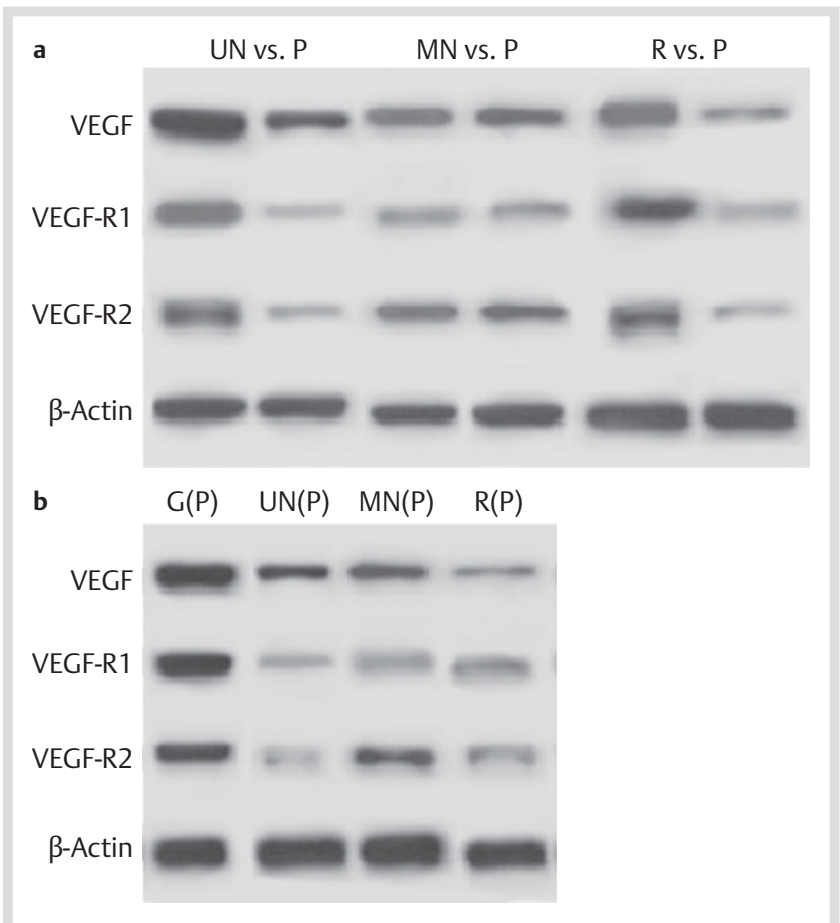

Fig. 3 Protein expression of VEGF, VEGFR-1 and -2 of cellular lysates from primary culture of thyrocytes analyzed by western blotting. Depicted was 1 representative band from each group. a Expression in nodular $(\mathrm{UN}, \mathrm{MN}, \mathrm{R})$ vs. their corresponding paranodular tissue (P). b Paranodular tissue of Graves'disease $(G)$ vs. paranodular tissue of uninodular, multinodular and recurrent goiter (UNP, MNP, RP).

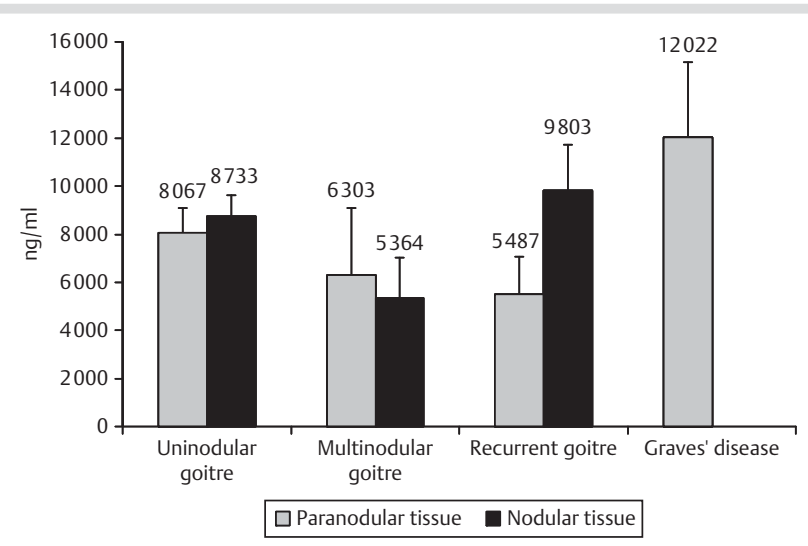

Fig. 4 VEGF expression in supernatant of primary culture of thyrocytes from nodular and paranodular tissue determined by ELISA. $n=$ (nodu$\operatorname{lar}=38$ : paranodular $=36)$, results are expressed as mean \pm SEM.

so far. Jebreel et al. reported no differences in VEGFR-1 and -2 expression between the different thyroid pathologies, so the author suggested that up-regulation of VEGF and not of its receptors was important in the development of thyroid diseases [30]. In contrast to our findings, we demonstrated significantly higher expression of the 2 receptors in nodular tissue of uninodular and recurrent goiter compared to corresponding normal tissue both in mRNA and protein level. These results might indicate, that not only up-regulation of VEGF, but also up-regulation of its receptors plays a critical role in the development of goiter. In addition to receptor expression, we were able to detect significant amount of VEGF in the supernatant of thyrocytes culture.
Consistent with our data, Sato et al. reported high levels of VEGF in cyst fluid of thyroid nodules. They postulated that VEGF was secreted by thyrocytes and that it was involved in the pathogenesis of cyst fluid accumulation [31].

In the present study, we were able to detect an active secretion of VEGF by human thyrocytes and simultaneous expression of both VEGF receptors. This coexpression of VEGF and its receptors raises the possibility that VEGF may act in an autocrine loop in thyrocytes, as observed previously in thyroid cancer [32].

Perhaps, an autocrine stimulation plays a crucial role in proliferation of thyrocytes and such up-regulation of the VEGF signaling might be involved in the development of nodular goiter. Besides, high levels of VEGF and its receptors in recurrent nodules may pose potential risk for the development of goiter recurrence.

It is also known, that autocrine stimulation of VEGF receptors leads to enhanced tumor growth [33]. This mechanism, initiated by increased VEGF expression, may also be involved in the growth of thyroid nodules and goiter recurrence.

In our study, we did not find any differences in gene or protein expression of VEGF and its receptors between nodular and paranodular tissue of patients with multinodular goiter, but instead detected an increased concentrations of the growth factor in both tissues. Therefore, we postulated, that in multinodular goiter the entire tissue of the thyroid gland might be pathologically altered and are not only limited in the circumscribed nodules. Although the cause of recurrence might be of multifactorial origin, elevated expression of VEGF and its receptors might also contribute to the high rate of recurrence of over $20 \%$ of multinodular goiter after subtotal resection [34-36], Our findings are also in accord with clinical studies which assumed an involvement of the whole thyroid parenchyma in benign disease and therefore, recommended total thyroidectomy as a suitable treatment [37].

Furthermore, we examined tissue from 10 patients with Graves' disease. In the literature, contradictory data are reported on VEGF expression in this autoimmune disease of the thyroid gland. However, several authors could not detect any expression of VEGF in Graves' disease in immunohistochemical staining [29] or only at lower levels compared to neoplastic tissue [30] and so argued that VEGF signaling plays only a minor role in the development of autoimmune disease of the thyroid gland. On the other hand, litaka et al. reported increased serum VEGF levels in patients with Graves' disease compared to healthy persons [38]. Furthermore, studies demonstrated a positive correlation between VEGF levels and increased vascular density in Graves' disease [39] as well as strong expression of VEGF in hyperplastic follicular cells and surrounding capillaries [40], indicating a link between epithelial function and microcirculation.

In concordance with these data, we have detected in our study high levels of VEGF and its receptors both in MRNA and protein in monocultures of thyrocytes obtained from patients with Graves' disease. Here, we have shown that the expression was significantly increased compared with the other groups.

These results may indicate that VEGF is involved in the pathogenesis of Graves' disease and may have an influence on both epithelial proliferation and thyroid microcirculation, causing a typical hypervascularization and hyperplasia seen in this autoimmune disease. Moreover, this might be a first hint, that VEGF might also be involved in the control of thyroid function. Besides the up-regulation of VEGF in goiter, the present study was able to confirm the expression of VEGF and its receptors in 
normal thyroid tissue. Clinical studies have also reported, that over $40 \%$ of patients treated with tyrosine kinase inhibitors (TKI) developed hypothyroidism [24,25]. Recently Sato et al. reported a sonographically detectable atrophy of the thyroid gland caused by sunitinib therapy [41]. One hypothesis for TKIrelated hypothyroidism is inhibition of the VEGF-pathway resulting in reduction of capillary blood flow. These observations and data may signify that VEGF signaling might participate not only in thyroid hyperplasia but is also essential in normal thyroid function as well as physiological proliferation of thyrocytes.

\section{Conclusion}

$\nabla$

In summary, our study showed an increased expression of VEGF and its receptors in nodular tissue of uninodular and recurrent goiter as well as in the entire tissue of multinodular goiter and Graves' disease. Therefore, we hypothesized that VEGF may be involved in the proliferation of thyrocytes and its up-regulation via autocrine mechanism might contribute to the development of thyroid nodules and hyperplasia of the thyroid gland.

Although, it is very likely that goiter recurrence is of multifactorial origin, VEGF may serve as a proliferation marker in thyroid disease and may be used as a possible target for future strategies for the treatment of neoplastic and autoimmune diseases of the thyroid. Until now, the exact role of VEGF in thyroid function remains to be determined. Hence, more future studies are eminent to elucidate the role of VEGF in thyroid diseases.

\section{Conflict of interest: None.}

\section{References}

1 Ferrara N, Henzel WJ. Pituitary follicular cells secrete a novel heparinbinding growth factor specific for vascular endothelial cells. Biochem Biophys Res Commun 1989; 161 (2): 851-858

2 Ferrara N, Houck K, Jakeman L et al. Molecular and biological properties of the vascular endothelial growth factor family of proteins. Endocr Rev 1992; 13 (1): 18-32

3 Ferrara $N$. Vascular endothelial growth factor: basic science and clinical progress. Endocr Rev 2004; 25 (4): 581-611

4 Ferrara $N$, Davis-Smyth $T$. The biology of vascular endothelial growth factor. Endocr Rev 1997; 18 (1): 4-25

5 Takahashi H, Shibuya M. The vascular endothelial growth factor (VEGF)/VEGF receptor system and its role under physiological and pathological conditions. Clin Sci (Lond) 2005; 109 (3): 227-241

6 Kakeji Y, Koga T, Sumiyoshi $Y$ et al. Clinical significance of vascular endothelial growth factor expression in gastric cancer. J Exp Clin Cancer Res 2002; 21 (1): 125-129

7 Scott PA, Smith K, Poulsom $R$ et al. Differential expression of vascular endothelial growth factor mRNA vs protein isoform expression in human breast cancer and relationship to eIF-E4. Br J Cancer 1998; 77 (12): 2120-2128

8 Konno H, Tanaka T, Baba M et al. Quantitative analysis of vascular endothelial growth factor in colon cancer. Clinical and experimental. Eur Surg Res 1998; 30 (4): 273-278

9 Hatenbach EM, Olson TA, Goswitz JJ et al. Vascular endothelial growth factor (VEGF) expression and survival in human epithelial ovarian carcinomas. Cancer Lett 1997; 121 (2): 169-175

10 Strohmeyer D, Strauss F, Rössing $C$ et al. Expression of bFGF, VEGF and c-met and their correlation with microvessel density and progression in prostate carcinoma. Anticancer Res 2004; 24 (3a): 1797-1804

11 Maeda K, Chung YS, Ogawa $Y$ et al. Prognostic value of vascular endothelial growth factor expression in gastric carcinoma. Cancer 1996; 77 (5): 858-863

12 Feng $Y$, Wang $W$, Hu $J$ et al. Expression of VEGF-C and VEGF-D as significant markers for assessment of lymphangiogenesis and lymph node metastasis in non-small cell lung cancer. Anat Rec (Hoboken) 2010; 293 (5): 802-812
13 Xiang Z, Zeng Z, Tang $Z$ et al. Increased expression of vascular endothelial growth factor- $C$ and nuclear CXCR4 in hepatocellular carcinoma is correlated with lymph node metastasis and poor outcome. Cancer J 2009; 15 (6): 519-525

14 Morales-Gutiérrez C, Abad-Barahona A, Moreno-González E et al. Tumour VEGF/non tumour VEGF protein expression ration as a biomarker for survival in colorectal cancer patients. Eur J Surg Oncol 2011; 37 (6): 526-531

15 Valachis A, Polyzos NP, Patsopoulos NA et al. Bevacizumab in metastatic breast cancer: a meta-analysis of randomized controlled trials. Breast Cancer Res Treat 2010; 122 (1): 1-7

16 Yakes FM, Chen J, Tan J et al. Cabozantinib (XL184), a novel MET and VEGFR2 inhibitor, simultaneously suppresses metastasis, angiogenesis, and tumor growth. Mol Cancer Ther 2011; 10 (12): 2298-2308

17 Klein M, Picard E, Vignaud JM et al. Vascular endothelial growth factor gene and protein: strong expression in thyroiditis and thyroid carcinoma. J Endocrinol 1999; 161 (1): 41-49

18 Turner HE, Harris AL, Melmed $S$ et al. Angiogenesis in endocrine tumors. Endocr Rev 2003; 24 (5): 600-632

19 Capp C, Wajner SM, Siqueira DR et al. Increased expression of vascular endothelial growth factor and its receptors, VEGFR-1 and VEGFR-2, in medullary thyroid carcinoma. Thyroid 2010; 20 (8): 863-871

20 Erdem H, Gündogdu C, Sipal S. Correlation of E-cadherin, VEGF, COX-2 expression to prognostic parameters in papillary thyroid carcinoma. Exp Mol Pathol 2011; 90 (3): 312-317

21 Karaca Z, Tanriverdi $F$, Unluhizarci $K$ et al. VEGFR1 expression is related to lymph node metastasis and serum VEGF may be a marker of progression in the follow-up of patients with differentiated thyroid carcinoma. Eur J Endocrinol 2011; 164 (2): 277-284

22 Lennard CM, Patel A, Wilson J et al. Intensity of vascular endothelial growth factor expression is associated with increased risk of recurrence and decreased disease-free survival in papillary thyroid cancer. Surgery 2001; 129 (5): 552-558

23 Deshpande H, Roman S, Thumar J et al. Vandetanib (ZD6474) in the treatment of medullary thyroid cancer. Clin Med Insights Oncol 2011; 5: $213-221$

24 Mannavola D, Coco P, Vannucchi G et al. A novel tyrosine-kinase selective inhibitor, sunitinib, induces transient hypothyroidism by blocking iodine uptake. J Clin Endocrinol Metab 2007; 92 (9): 3531-3534

25 Brown RL. Tyrosine kinase inhibitor-induced hypothyroidism: incidence, etiology, and management. Target Oncol 2011; 6 (4): 217-226

26 Hsueh C, Lin JD, Wu IC et al. Vascular endothelial growth factors and angiopoietins in presentations and prognosis of papillary thyroid carcinoma. J Surg Oncol 2010; 103 (5): 395-399

27 Bunone G, Vigneri P, Mariani L et al. Expression of angiogenesis stimulators and inhibitors in human thyroid tumors and correlation with clinical pathological features. Am J Pathol 1999; 155 (6): 1967-1976

28 Tanaka K, Kurebayashi J, Sonoo $H$ et al. Expression of vascular endothelial growth factor family messenger RNA in diseased thyroid tissues. Surg Today 2002; 32 (9): 761-768

29 Itoh A, Iwase K, Jimbo $S$ et al. Expression of vascular endothelial growth factor and presence of angiovascular cells in tissues from different thyroid disorders. World J Surg 2010; 34 (2): 242-248

30 Jebreel A, England J, Bedford $K$ et al. Vascular endothelial growth factor (VEGF), VEGF receptors expression and microvascular density in benign and malignant thyroid diseases. Int J Exp Pathol 2007; 88 (4): 271-277

31 Sato K, Miyakawa M, Onoda $N$ et al. Increased concentrations of vascular endothelial growth factor/vascular permeability factor in cyst fluid of enlarging and recurrent thyroid nodules. J Clin Endocrinol Metab 1997; 82 (6): 1968-1973

32 Vieira JM, Santos SC, Espadinha C et al. Expression of vascular endothelial growth factor (VEGF) and its receptors in thyroid carcinomas of follicular origin: a potential autocrine loop. Eur J Endocrinol 2005; 153 (5): 701-709

33 Fan F, Wey JS, McCarty MF et al. Expression and function of vascular endothelial growth factor receptor-1 on human colorectal cancer cells. Oncogene 2005; 24 (16): 2647-2653

34 Vaiman M, Nagibin A, Hagag $P$ et al. Subtotal and near total versus total thyroidectomy for the management of multinodular goiter. World J Surg 2008; 32 (7): 1546-1551

35 Snook KL, Stalberg PL, Sidhu SB et al. Recurrence after total thyroidectomy for benign multinodular goiter. World J Surg 2007; 31 (3): 593-598

36 Moalem J, Suh I, Duh QY. Treatment and prevention of recurrence of multinodular goiter: an evidence-based review of the literature. World J Surg 2008; 32 (7): 1301-1312 
37 Basili G, Biagini C, Manetti A et al. Risk of recurrence following partial thyroidectomy for benign lesions. Report of 58 patients $15-25$ years after surgery. Minerva Chir 2003; 58 (3): 321-329

38 Iitaka M, Miura S, Yamanaka $K$ et al. Increased serum vascular endothelial growth factor levels and intrathyroidal vascular area in patients with Graves' disease and Hashimoto's thyroiditis. J Clin Endocrinol Metab 1998; 83 (11): 3908-3912

39 Nagura S, Katoh R, Miyagi E et al. Expression of vascular endothelial growth factor (VEGF) and VEGF receptor-1 (Flt-1) in Graves disease possibly correlated with increased vascular density. Hum Pathol 2001; 32 (1): 10-17
40 Gérard AC, Denef JF, Many MC et al. Relationships between cell division, expression of growth factors and microcirculation in the thyroids of Tg-A2aR transgenic mice and patients with Graves' disease. J Endocrinol 2003; 177 (2): 269-277

41 Sato S, Muraishi K, Tani J et al. Clinical characteristics of thyroid abnormalities induced by sunitinib treatment in Japanese patients with renal cell carcinoma. Endocr J 2010; 57 (19): 873-880 